Ann. Biol. anim. Bioch. Biophys., I975, 15 (2), 48I-492.

\title{
THE COLLOQUIUM IN PERSPECTIVE
}

\author{
T. J. ROBINSON \\ Department of Animal Husbandry, University of Sydney, \\ N.S. W., Australia 2006
}

If it has done nothing else, this Colloquium has brought out the complexity of the issues - scientific, economic, social, and practical - involved in the successful development and application of new techniques for controlled breeding of domestic livestock. Basic physiological principles, practical results of experiments, and problems associated with application are inextricably interwoven.

Following a logical sequence, the Colloquium dealt with (I) modern concepts of endocrinology of sexual cycles, luteolysis and ovulation, (2) a discussion of principles involved in the control of ovulation, and (3) methods used for the control of cycles in all species. It emerged that major factors limiting the practical success of methods of controlling the sexual cycles - and fertility - of domestic animals are (4) the physiological state of the animals at the time of treatment and (5) practical problems associated with implementing a programme of controlled breeding.

\section{I. - ENDOCRINOLOGY OF SEXUAI, CYCIES, LUTEOLYSIS AND OVULATION}

Discussion centred mainly around the role of the prostaglandins in luteal rugression, and ovulation and oocyte maturation. Dr. THORBURn gave us a clear exposition of the role of $\mathrm{PGF}_{2 \alpha}$. He put forward the counter current hypothesis, showed the necessity for relatively prolonged action of $\mathrm{PG}$ for complete luteal regression, and presented evidence that, at least in the pregnant goat, oestradiol- $I 7 \beta$ is the active agent causing release of $\mathrm{PGF}_{2}$. Luteal regression following exogenous $\mathrm{PG}$ is more rapid than in a normal cycle. Dr. HANSEL pursued the question of the role of PG in 1uteolysis and pointed out that regression of the corpus luteum is an active process and presented evidence that oestrogen of follicular origin is involved in prostaglandin induced luteolysis. Perhaps one of the most convincing pieces of evidence for the active role of $\mathrm{PG}$ - direct or indirect - was presented by Drs. BAIRD and ScARAMUzzr who showed that $\mathrm{PGF}_{2}$-induced luteal regression could be prevented by immunization. They conclude that initiation of luteolysis is an active phenomenon which does not involve changes in blood flow, although such changes may be involved 
in the final demise of the corpus luteum. Two reports, that of THORBURN and that of Mme CORTEEL and Dr. ThImoniER, provide evidence that exogenous $\mathrm{PGF}_{2} \alpha$ has a direct and dramatic effect on steroid synthesis whereas normal luteolysis involves more gradual degenerative changes affecting the whole secretory cell. The appearance of dense granular bodies within such a cell - as shown by electron microscopy coincides with the appearance of progesterone in the blood and these bodies disappear rapidly following treatment with exogenous $\mathrm{PGF}_{2} \alpha$.

Dr. Armstrong presented evidence that $\mathrm{PGF}_{2 \alpha}$ has a role in addition to that of a luteolysin, namely in ovulation and oocyte maturation. He has shown that the level of $\mathrm{PGF}_{2}$ increases in follicular fluid of the definitive follicle during pro-oestrus and that ovulation can be blocked with either indomethacin or anti-PGF 2 , and suggests a finely balanced relationship between $\mathrm{LH}$ and $\mathrm{PGF}_{2} \alpha$ in the process of ovulation. Be that as it may, the sequence of events summarized by Drs. PELLETIER and Thimonier are clearly involved. Oestradiol release results in a surge of LH, a surge which is not induced by a decline in progesterone. The probable role of pituitary gonadotrophin (FSH) in the sudden release of oestrogen is indicated by the fact that it can be induced by PMSG. Of particular interest is their demonstration of a critical progesterone/oestrogen plasma ratio on the response of the pituitary to GnRH. "Hormone balance " is becoming fashionable again and its importance needs to be recognised in relation to the balance between the ovarian steroid hormones and the influence of this balance on hormones which act directly upon the ovary (viz. $\mathrm{I}, \mathrm{H}$ and $\mathrm{PGF}_{2}$ ) and which are involved in ovulation.

\section{2. - PRINCIPLES IN THE CONTROL OF OVULATION}

A major topic was the reason for the commonly observed subfertility following control of ovulation. Much of this section dealt with ovarian and other changes following a number of methods of control in the cyclic animal. There is conflicting evidence of temporal changes in events such as time of production of oestrogen, onset of oestrus, release of $\mathrm{LH}$, ovulation, and rate of cleavage of ova following such control. These are confusing and cloud the important issues of the reason for this sub-fertility and, most important, what is a "normal " sequence of events and what is "normal " fertility.

In our laboratory we have no evidence of an abnormal time of ovulation in sheep following progestagen controlled cycles. There have been reports, notably one from the late Dr. Goding's laboratory, of early release of $\mathrm{LH}$ following withdrawal of progestagen impregnated intravaginal sponges and of abnormal times of onset of oestrus relative to time of ovulation. Such reports are difficult to interpret because of the quantitative relationships between factors such as the magnitude of production of oestrogen and hence the time of onset of oestrus, the relative constancy of the time interval between peak oestrogen production and $\mathrm{LH}$ release, and methods used for determining the time of onset of oestrus and of ovulation.

This meeting has produced another series of apparently conflicting reports. Thus Dr. KRUIP has presented evidence that MAP treatment to sheep results in a pattern of ovarian morphology which differs from normal, associated with maximum 
production of oestrogen on the day of oestrus and not on the day before. This would mean ovulation later than normal. On the other hand, Mr. WISHART concludes that the time of ovulation in heifers is not affected by progestagen treatment, and time relationship between progestagen withdrawal, oestrus and ovulation are normal but the rate of cleavage of fertilized eggs is slightly slower than normal. Likewise Drs. SignoRET and COGNIE conclude that the time of ovulation in sheep is not affected by intravaginal FGA treatment - a conclusion in line with our own. They have presented two useful new pieces of data. The first is the evidence that, although injection of PMSG results in an earlier surge of $\mathrm{LH}$ and an overall improvement in synchronization, there is a heterogeneity of response indicating two populations of follicles in the ovary. The second and exciting observation, made with Dr. David LINDSAY, is that the presence of rams permanently with ewes advances the time of $\mathrm{LH}$ release and hence of ovulation. Similarly with the sow, the presence of the boar increases the synchrony between ovulations.

Recognition of such interactions between treatment and intrinsic factors such as the state of the follicle population and extrinsic factors such as the relationship between male and female may help to explain some of the apparent paradoxes.

The next major topic was the control of ovulation in cattle using combinations of GnRH, progestagen, and prostaglandin. Dr. BRITT showed that ovulation can be induced by GnRH in post-parturient cows as early as I4 days after calving. Two papers showed the promise of intravaginal progestagen for control of the time of ovulation in cyclic cows. Drs. MAUER, WEBEL and Brown and Dr. Roche reported on results obtained following the use of a new intravaginal device impregnated with progesterone (PRID), followed by the injection of GnRH. Retention rates of the order of $90 \mathrm{p}$. Ioo associated with good synchronization and fertility were reported. These data are comparable with those recently published by Dr. John Smith of Ruakura, New Zealand, who has used intravaginal sponges impregnated with Cronolone. As with the sheep, it is clear that ovarian stimulation with exogenous $\mathrm{GnRH}$ or gonadotrophin following progestagen is necessary to improve the degree of synchronization and to reduce the incidence of " silent heats ". The percentage of "silent heats " is not increased by treatment and it appears that their importance in the normal cyclic animal has not been appreciated.

Dr. PHILIIPPo dealt with the question of the variability of response to PMSG used for superovulation in cattle and showed that some of this variability may be reduced by an appropriate combination of treatments with prostaglandin and PMSG.

In this general context, I believe it is a pity that the vast amount of data collected by our French colleagues, and published in monograph form, showing the response to PMSG of cattle by season, breed, strain and region, is not more widely known and has not been brought to the fore at this Colloquium.

\section{3. - METHODS USED FOR THE CONTROL, OF CYCLES}

Methods of control which have been discussed fall into four categories, namely :

a. Prolongation of the normal luteal phase of the cycle or establishment of an artificial luteal phase by exogenous progestagen. 
$b$. Shortening of the normal luteal phase by exogenous prostaglandin.

$c$. Control of the breeding cycle by artificial lighting.

d. Induction of ovulation using $\mathrm{GnRH}$.

Both $a$. and $b$. are applicable to cyclic lactating or non-lactating animals with or without the additional use of gonadotrophin or $\mathrm{GnRH}$ but only the former to the prepubertal or anoestrous ruminant, in which gonadotrophin is essential. Method $c$. is concerned with control under housing conditions, while method $d$. is restricted to that proportion of anoestrous or post-parturient animals in which the pituitary can respond to releasing factor.

\section{A. - Prolongation of the luteal phase}

This has been the classical method of synchronizing oestrus in the cyclic cow, sheep and goat and, with PMSG, for inducing a controlled cycle in the anoestrous sheep and goat. This meeting has heard reports on the use of the three methods of administration now in use or under investigation, namely the (i) intravaginal, (ii) subcutaneous or (iii) oral route.

\section{(i) Intravaginal.}

The intravaginal use of Cronolone (Searle) is now becoming widely applied commercially in sheep and goats in Europe and, as indicated by Dr. ORTAVANT, some 300,000 ewes are to be treated in I974. Drs. ColAs and CORTEEI have shown that the additional use of PMSG in the ewe and goat in the breeding season results in more precise and reliable synchronization, enabling fixed time insemination 48 and 60 hours after removal of the progestagen impregnated sponge and injection of PMSG. There still remains the problem of impaired sperm transport, necessitating the use of excessive numbers of spermatozoa $\left(250-500 \times 10^{6}\right)$ at each insemination. The use of frozen semen, reconstituted to provide a high density inseminate, is possible, particularly in the goat where intrauterine insemination is possible. One important aspect of their work, as shown originally in our laboratory and by Dr. GoRDon, is the necessity for an adequate progestagen regime before PMSG. A high level of progestagen followed by rapid withdrawal and adequate ovarian stimulation is a necessary prerequisite for acceptable fertility.

Intravaginal application of progesterone or of Cronolone to heifers and cows also offers promise, as discussed above.

\section{(ii) Subcutaneous.}

We had four reports on the subcutaneous implant technique in cattle. Fach involved short term treatment with a highly active progestagen (SC-2I009, Searle) following a high dose of oestrogen to cause luteolysis of an existing corpus luteum. Dr. MAREs' paper showed that $\mathrm{E}_{2}$ disappeared very rapidly from the blood whereas conjugated forms of oestrogen resulted in measurable levels for 5 or 6 days. Five of the $6 \mathrm{mg} \mathrm{SC-2IOOg}$ in the implant was absorbed over a 9 day period, and it disappeared rapidly from the blood after removal. It is curious that a measurable level of oestrogen up to 3 or 4 days before removal of the progestagen implant did not depress fertility. Thus Mr. Wishart and Drs. Wiltrank and Gonzalez-Padili,a each 
reported upon synchronization and fertility following use of this technique in heifers and their data justify hopes that fixed time insemination may be a possibility. Neither used GnRH or exogenous gonadotrophin following removal of the implants. Drs. Chupin, Petot and Thimonier found that short (9 day) treatment with SC2 Ioog following oestradiol valerate and followed by the injection of 800 IU PMSG gave optimum results. Further, as in the sheep, a high dose of progestagen is important and the optimum combination of treatments resulted in a calving rate to one insemination of $67 \mathrm{p}$. roo, or $83 \mathrm{p}$. Ioo over a 30 day insemination period.

There was also discussion concerning the necessity or otherwise of large doses of oestrogen prior to progestagen to induce luteolysis. The paper of CHUPIN et al. showed that such an injection increased efficiency of synchronization and percentage of births. Dr. LEMon's paper showed that oestrogens may have a variety of effects on the corpus luteum - luteotrophic, luteolytic or anti-luteolytic — depending on factors such as dose, day of treatment and duration of activity of the oestrogen in use. A similar multiplicity of effects has been shown in our laboratory with the sheep, indicating the need for a clear definition of the parameters associated with oestrogen use and effect.

The key to the use of the WILTBANK technique lies in the use of a dose and type of oestrogen of sufficient size and duration of activity to cause complete luteolysis of a corpus luteum (if present). Further, the oestrogen must disappear completely a few days before withdrawal of the artificial progestational phase.

(iii) Oral.

There were but two reports on the use of oral progestagen in cattle. The first was that of Dr. JOCHLE on the use of Chlormadinone in the tropics. While it is now generally recognised that the use of oral progestagens will result in oestrus " grouping " rather than synchronization, two important questions of principle emerged from this paper. First of all, under the rather primitive husbandry conditions that he was describing, the feed incorporating the oral progestagen probably had a "flushing " effect on ovulation and, secondly, the ultimate overall fertility of the treated herds was better than that of the untreated due to the greater attention paid to management and mating procedures. Dr. GRUNERT's paper confirmed the observation of Dr. JOCHLE, and others, that progestagen treatment improved reproductive performance overall by reducing the number of anoestrous animals. Further, the use of GnRH with fed CAP improved the pattern of response.

\section{B. - Shortening of the luteal phase}

The characteristics of the $\mathrm{I}_{5}$ or so naturally occurring $\mathrm{PGs}$ were described by Dr. WALPOLE, who also presented us with data on several analogues which are highly active when administered systemically. Their potential use is restricted to the normal cycle and, within the cycle, they are limited to use where there is an active and sensitive corpus luteum. Dr. Polge has shown how such corpora lutea may be set up in the pig either by induction of supernumerary corpora lutea or by pregnancy.

In the cow, $\mathrm{PGF}_{2}$ appropriately administered causes rapid luteolysis between days 5-I6 of the cycle, as shown by Drs. Louis, Hafs and STILLFLug, Dr. LAUdERDALE, and Dr. MOORE. The spread of oestrus is too great for fixed time insemination 
and highest fertility is observed in cows in oestrus 2 to 4 days after injection. Complete luteolysis is not always achieved and, unless a level below $2 \mathrm{ng} / \mathrm{ml}$ of progesterone is achieved rapidly, subsequent incidence of ovulation, oestrus and fertility is impaired. Applying these principles, Dr. Cooper and Mr. Rowson have used two injections of ICI-80,996 - a synthetic PG - spaced IO-I2 days apart. Preliminary results have been most encouraging. A similar treatment has been applied by ThImonier et al. resulting in 80 to $90 \mathrm{p}$. IOO of cows in oestrus after treatment.

The corpus luteum of the mare is highly sensitive to PG as shown by Dr. ALLEN and by Drs. PALMER and Jousser. Sequential treatment with PG and HCG seems a promising method of controlling the time of ovulation and, as shown by ALLEN, of overcoming the problem of retained corpora lutea, a serious cause of infertility in thoroughbred mares.

\section{C. - Control by artificial lighting}

The most reliable results of controlled breeding were reported by Dr. John RoBINson who has used controlled photoperiod to induce a breeding season every seven months in ewes, associated with intravaginal progestagen impregnated sponges for controlling the time of oestrus within each of the short induced seasons. He has removed the complication of lactation by weaning at one month and has succeeded in getting 90-95 p. Ioo of his ewes pregnant within the next month. This is an excellent model for the study of all the basic parameters associated with the control of breeding phenomena in ruminants.

\section{D. - Induction of ovulation using $G n R H$}

The Colloquium illustrated the potential values as well as the limitations of GnRH. Potential advantages are availability, relative simplicity of structure, and hence consistency, and cheapness. Disadvantages lie in the variability of the animals in which they are to be used and the ability of the pituitary to respond. PELLETIER and THImonIER have shown that the post-parturient pituitary of the sheep cannot fully respond to GnRH, whereas BRITT has shown that first post-parturient ovulation in the cow may be advanced by Io days and that ovulation may be induced in the mare and the prepubertal gilt. By contrast, Dr. BAKER finds it to be no substitute for PMSG-HCG treatment in the gilt. BRITT and PELIETIER and THIMONIER find that $\mathrm{I}_{\mathrm{H}} \mathrm{H}$ release is not possible in the presence of an active corpus luteum.

It is difficult to assess the potential value of synthetic $\mathrm{GnRH}$ in the overall context of control of sexual cycles in domestic animals. It can only operate when the pituitary is "loaded" and so in many instances is no substitute for PMSG, HCG or HAP. It is clear, from the reports of GRUNERT, ROCHE and MAUER et al., that in some circumstances it is a substitute. Its use in association with progestagen for synchronizing oestrus in cattle has resulted in a hastening of the time of ovulation and an increase in precision.

The study of the characteristics and potential of the releasing factors is in its infancy, and it will be many years before it reaches adulthood. It must be recognised that they are much finer tools than such blunt endocrinological instruments as 
PMSG, HCG and HAP. Hence it can be expected that their specificity of action will be greater, their variability of response in clearly defined situations less, and their adaptability and range of action narrower than that observed following the use of the commonly used gonadotrophins. The key to their potential use lies in clearly defining the situation - notably the state of the pituitary - in which their use is proposed.

\section{4. - PHYSIOLOGICAL S'TATE OF THE ANIMAL WHEN TREATED}

Control of sexual cycles of domestic animals is far more difficult than control of cycles in the human, primarily because there are five distinct physiological states, each of which presents its own problems, namely :
a. Prepubertal
b. Anoestrous, non-lactating
c. Anoestrous, lactating
d. Cyclic, non-lactating
e. Cyclic, lactating.

This meeting has had reports dealing with each of these states from which it is apparent that control of the cycle followed by acceptable fertility is relatively simple using several techniques in the cyclic non-lactating animal but is considerably more difficult in the cyclic lactating animal, particularly within 40 days or so of parturition. Initiation of controlled cycles accompanied by acceptable fertility is feasible in anoestrous non-lactating and in prepubertal animals, using a more restricted range of techniques, but it is exceedingly difficult in the anoestrous lactating animal.

While these principles are generally recognised, only our French colleagues have systematically gone about investigating the fundamental problems of control in each of the five physiological states.

\section{A. - The prepubertal animal}

Pelimeter and Thimonier have shown that the prepubertal lamb of 38 days of age is capable of an oestrogen induced release of L.H. A similar phenomenon has been reported by BRITT for the prepubertal mare and gilt treated with GnRH, but as BAKER has pointed out there are difficulties associated with such treatment in the prepubertal gilt. The lamb is well able to respond to progestagen-PMSG treatment and to ovulate, exhibit oestrus and conceive at 6 months and lamb before she is I2 months old, as shown by Thrmonier et al. in their brief account of work in the Nouzilly flock and in the field.

To conclude, prepubertal breeding is a feasible proposition in the sheep, and possibly in the pig, but, on present information, exogenous GnRH is no substitute for the exogenous gonadotrophins, PMSG and HCG. 


\section{B. - The anoestrous non-lactating animal}

The sheep and goat are the two species with which we are concerned. The pituitary of the anoestrous sheep is highly sensitive to oestrogen and, as shown by PELLETIER and THImoniER, releases a large quantity of $\mathrm{LH}$ when stimulated by oestrogen. One is reminded of the demonstration some 30 years ago by John HAmmond Jnr. that ovulation could be induced in a proportion of anoestrous ewes by a single injection of stilboestrol. This effect is mediated via a release of $\mathrm{GnRH}$, showing that in the anoestrous animal there is adequate $\mathrm{GnRH}$ and $\mathrm{LH}$ to permit normal ovulation, provided that the follicle stimulating-oestrogen production mechanisms are initiated.

These observations have been confirmed in practical terms by GoRdon, CoLAs, and COR'TEEL, who have shown the high degree of reliability of induction of synchronized breeding activity in the ewe and goat using a combination of progestagen priming by intravaginal sponges followed by PMSG. This technique seems unlikely to be replaced in the immediate future.

\section{C. - The anoestrous lactating animal}

This situation applies to the cow, sheep, goat and pig, and poses the greatest challenge to workers in the field of control of sexual cycles. That it applies to the cow is not as widely recognised as it should be. The demonstration by JOCHLE of a marked seasonality in the breeding pattern of cows in Mexico, at a latitude of only $2 I^{\circ} \mathrm{N}$, is most important. Artificial manipulation of the oestrous cycle results in an incipient sub-fertility associated with factors such as an impaired pattern of sperm transport and survival, and lowered rates of fertilization. This situation is exacerbated when control of the cycle is imposed during a season of the year when normal breeding activity is at a relatively low ebb. Add to a state of "relative " anoestrus in the cow the stress of lactation and inadequate nutrition and one has a true lactation anoestrus. To my knowledge, the duration and "depth" of this anoestrus in different seasons of the year has not been studied in any detail. This is a serious omission in relation to the detail of developing an effective means of control of the cycle in the milking dairy cow and the suckling beef cow under a variety of nutritional states. The data of BRITT show that the pituitary of the cow, which at parturition has been almost completely denuded of $\mathrm{L}, \mathrm{H}$, has made at least a partial recovery in two weeks. By analogy with the sheep and goat it seems that one must distinguish between the lactating milked cow and the lactating suckled cow and also between breeds according to their environment. Thus CHUPIN ct al. have pointed out the presence of a pronounced lactation anoestrus in the SALERS breed in France, so that control of the sexual cycle involves induction of synchronized breeding activity rather than control of established cycles.

Although John RoBinson has been more effective than any of us in breeding the post-parturient ewe, using controlled lighting, his ewes have not been lactating when joined. Even under his highly controlled conditions, it has not been possible to induce a fertile controlled mating within 40 days of parturition and the mean lambing interval is 205 days. Part of the problem in obtaining pregnancy within one month of parturition lies in the time needed for complete involution of the 
reproductive tract but also, as shown by PEILETIER and THIMONIER, LH release following administration of oestrogen to the lactating ewe is less than normal. Nevertheless, ovulation can regularly be induced in such ewes by PMSG, as shown by Thimonier et al. and in the film shown by M. LE PREvost.

A basic factor involved in the difficulties associated with controlled breeding of the lactating animal is the low pituitary content of $\mathrm{LH}$ and its consequent relative failure to respond to GnRH. Mr. JAUME, in our laboratory, collected pituitaries from post-parturient ewes and these, when assayed for LH in Dr. GodING's laboratories, were found to be almost totally devoid of LH. PELIETIER and THIMONIER have told us that there is a markedly lower release of $\mathrm{LH}$ from lactating than from dry ewes whether one uses oestrogen, PMSG, or PMSG + GnRH. This is a key to the fundamental problem associated with controlled breeding of all species and highlights the need for detailed study of the $\mathrm{L} / \mathrm{H}$ releasing capacity of the lactating dairy cow or suckling beef cow in which control of the cycle is so important.

CoLAs mentioned the difficulty in obtaining pregnancy in the suckling ewe as compared with the non-suckling animal, an observation elaborated upon by Dr. CoGNIE who found the lowest fertility following controlled breeding in ewes suckling during the anoestrous period. This and other French work suggests a specific effect of suckling or maternal behaviour on a number of parameters of fertility, including the number and spread of ovulations, fertilization rate, and preimplantation loss of blastocysts. From both a fundamental and applied point of view this is a most important area for work using the sheep - or the goat - as a model for the study of a problem which must exist, albeit only partly recognised, in the high producing dairy cow or the suckling beef cow, particularly when calving in the period of the year when, as shown by JOCHLE, reproductive activity is at its lowest.

Lactation anoestrus is well recognised in the pig and the "depth" of this anoestrus, as shown by COGNIE for the sheep, is related to the number of piglets born and the milk production of the sow. Françoise MARTINAT-BOTTE showed the importance of level of lactation on all parameters of fertility and the interaction with post partum interval. Up to 25 days post partum it is easier to induce oestrus and ovulation in sows suckling less than 5 young than in sows suckling 5 or more.

One of the most pertinent things to emerge from the discussions involving the post partum lactating animal was the low pregnancy rates currently observed in all classes of farm livestock. American, French and British data all show that, far from the commonly accepted 65 percent conception rate in dairy cows, a $50 \mathrm{p}$. Ioo calving rate in untreated artificially inseminated cattle is the current normal expectation. Similar results were cited for suckling beef cows. Clearly there is a serious problem here which needs definition and it is clear, too, that many maligned progestagen treatments, where accurate fertility data have been obtained, are not as bad, vis a vis normal expectations, as had been believed. Several participants, notably Grunert, Jochle, LAuderdale, Hansei, and Rey, have pointed out that, following treatment of cattle with any form of progestagen, overall herd fertility is improved, due probably to factors such as greater attention to details of management and to a reduction in the numbers of "silent " heats.

In summary, lactation anoestrus - relative or absolute - is a serious problem in all types of farm animals and the initiation and control of sexual cycles in the lactating animal is particularly difficult. There are interactions between level of 
lactation, interval from parturition, whether suckled or not, number of young suckling, and nutritional state which render impossible generalisations concerning the manner of control and the degree of its efficacy.

\section{D. - Cyclic, non-lactating}

In this category are maiden cyclic animals of all types and, generally speaking, adult ewes and goat does. Control of the cycle associated with acceptable fertility of such animals is relatively simple as shown by the reports of CoLAS and COGNIE and the film of LE PREVOST. WiLTBANK and GONZALEZ-PADilila have shown equally good results in cyclic heifers treated with oestradiol valerate followed by an implant of the highly active progestagen SC-2 I009 (Searle).

Control of the cycle in the sow and mare may be achieved by the combined use of prostaglandin and gonadotrophin. Polge has shown that the corpus luteum of the sow is sensitive to $\mathrm{PG}$ only between the $\mathbf{I} 2$ th and $\mathbf{I} 5$ th day of the cycle but, if corpora lutea can be induced to persist beyond the $\mathrm{I} 5$ th day, they remain sensitive. Accessory corpora lutea may be induced at any stage of the cycle by the use of PMSG and HCG and these persist. Injection of PG I2 days later results in oestrus in some 80 p. Ioo of pigs 4-7 days later. Although not as precise as the methallibure-PMSG-HCG treatment, this technique does offer a means of oestrus "grouping " of potential value. A similar principle for controlling oestrus in the mare, described by PALMER and Jousset, has been mentioned.

\section{E. - The cyclic lactating animal}

The cow and sow are the two types of animal concerned in practice, but the data of COGNIE for the lactating ewe are pertinent. He has shown that (a) the number of young born affects the number of eggs fertilized at first oestrus, even if the lambs have been weaned and the erees are not lactating. In lactating ewes the number, fertilizability and survival of eggs produced is fewer than in non-lactating animals. However such eggs are viable if transferred to non-lactating ewes. That is, the reproductive tract of the lactating animal is less favourable to egg survival than that of the non-lactating animal. Comparable data have been presented by MarTinat-BotTe for the sow. The effect of stage and level of lactation in the cow was not dealt with specifically by any speaker, but its importance emerged from discussion.

\section{5. - PROBLEMS ASSOCIATED WITH COMMERCIAL IMPLEMENTATION OF CONTROLLED BREEDING}

A disappointing feature of the Colloquium was that few results were presented of widespread practical application. Exceptions were :

$a$. The film shown by LE PREvost on the work carried out by the team at Nouzilly, resulting in the I. N. R. A. system of controlled sheep breeding for all the year round production of lambs. 
b. The report by Goroon on the programme of early sheep breeding pioneered by himself and now conducted by the Irish I lepartment of Agriculture.

c. The report of CORTIEI, on the commercial use of Cronolone impregnated intravaginal sponges + PMSG, associated with artificial insemination and the use of frozen semen, for advancement of the breeding season of milch goats.

d. The paper of Mooks on the large scale application of $\mathrm{PGF}_{2 \alpha}$ for synchronization of oestrus in cattle for egg transfer for increasing the numbers of cattle of exotic breeds introduced into Australia.

It is clear, particularly from the experience of the Nouzilly group, that a great deal of care and attention to detail is necessary in order that a system of controlled breeding is introduced into animal industry. A method for controlled breeding of cattle, sheep, goats, or pigs is not a product which can be sold en masse like any pharmaceutical product. It must form part of a system of husbandry and be integrated into a whole production pattern. A method for horses may fall into a different category because of the value of individual animals and the fact that thoroughbred studs usually operate under close veterinary surveillance.

This principle is clearly brought ont by our experience with controlled sheep and goat breeding, so clearly enunciated by Gordon, illustrated by LE PrevosT's film, and dealt with in some of its details by Robinson, ColAs and CorTEEL. The Cronolone sponge technique was developed in my laboratory some Io years ago but has never been accepted commercially in Australia because of economic and practical difficulties of incorporating it into our husbandry practices.

Prerequisites for economic application are :

$a$. High value of individual animals and their products.

$b$. Economic advantage gained from increased prolificacy, particularly if associated with out of season production.

c. Adequate servicing, training and research facilities to take the process out onto the farm.

d. Recognition that introduction of one sophisticated innovation will demand the introduction of others, resulting in the development of whole new systems of production.

$e$. Fxistence of a high level of husbandry and understanding.

There needs to be an unbroken chain of operations from top research capacity to farm extension level. The I. N. R. A. system of controlled sheep and goat breeding is the classical example of the successful implementation of these principles in that it shows that the development of an effective method of control of the sexual cycle is but a part of the whole operation and that ultimate success depends upon the development of a fully coordinated and programmed system of operations. This system avoids weekend and holiday work, provides for a mild degree of artificially induced superovulation, builds in genetic parameters for high fecundity, involves the use of artificial insemination and frozen stored semen for genetic progress and convenience, incorporates early pregnancy diagnosis by blood progesterone assay at day I8, utilises induced synchronized parturition and artificial rearing of surplus lambs and, finally, induced ovulation with oestrus in lactating, anoestrous ewes to provide batch production of lambs at intervals of 49 days, on a year round basis. 
Similar principles will apply when technically and socially acceptable methods for controlled breeding are available for commercial use in cattle and pigs. As pointed out by Drs. LAMOND and LAUDERDAlE, and others at this meeting, such methods must be acceptable on the grounds of safety, public health, and freedom from hazards such, for example, as accidental abortion. Further, there must be safeguards against misuse in the hands of unscrupulous users - a big question mark when one considers the use of prostaglandins. When such methods do become available, this is only the start - an enormous amount of effort will still be required before they will be widely adopted. Fortunately we have the examples of the methods used by Dr. ORTAVANT's group here at Nouzilly and, on a more modest but no less courageous scale, by Dr. Gordon in Eire.

Colloque : Control of sexual cycles in domestic animals October 27-30, 1974, Nouzilly. 